\title{
Watermelon seeds and peels: fatty acid composition and cosmeceutical potential ${ }^{\text {th }}$
}

\author{
Arpa Petchsomrit ${ }^{1}$, Mark I. McDermott ${ }^{2}$, Salil Chanroj ${ }^{3}$ and Waeowalee Choksawangkarn ${ }^{4, *}$ \\ ${ }^{1}$ Faculty of Pharmaceutical Sciences, Burapha University, Chonburi 20131, Thailand \\ 2 Department of Molecular and Cellular Medicine, Texas A\&M Health Science Center, College Station, TX 77843-1114, USA \\ 3 Department of Biotechnology, Faculty of Science, Burapha University, Chonburi 20131, Thailand \\ ${ }^{4}$ Department of Biochemistry and Center of Excellence for Innovation in Chemistry, Faculty of Science, Burapha University, Chonburi \\ 20131, Thailand
}

Received 28 June 2020 - Accepted 16 September 2020

\begin{abstract}
Watermelon consumption results in generation of organic waste in the form of seeds and peels. We have evaluated the fatty acid profiles and antioxidant content of watermelon (Kinnaree cultivar) seed oil and peel wax. In addition, we assessed the potential use of these watermelon industry byproducts in the development of cosmeceuticals. The most abundant fatty acids in seed oil and peel wax were linoleic acid and arachidic acid, respectively. Fatty acids form an essential component in the cell membranes and have seen increased recognition in the cosmeceutical industry. Antioxidants also play a beneficial role in skincare in combating free-radicals resulting from sun damage and pollutants. The seed oil showed stronger antioxidant activity than the peel wax, as indicated by the DPPH radical scavenging ability of $0.894 \mathrm{mg} \alpha$-tocopherol equivalent/g dried seeds versus $0.036 \mathrm{mg} \alpha$-tocopherol equivalent/g dried peels. Therefore, the seed oil was formulated into skincare products, in the form of emulsions and nanoemulsions. The most effective formulae were stable at room temperature for seven days, or following repeated cycles of heating and cooling. This work demonstrates the potential for watermelon seed oil to be employed in skincare product formulations, which could maximize agricultural profit and minimize environmental waste.
\end{abstract}

Keywords: Watermelon / seeds / peels / antioxidant / nanoemulsion

Résumé - Graines et peaux de pastèque : composition en acides gras et potentiel cosmétique. La consommation de pastèques entraîne la production de déchets organiques sous forme de graines et de pelures. Nous avons évalué les profils d'acides gras et la teneur en antioxydants de l'huile de graines et de la cire de pelure de la pastèque (cultivar Kinnaree). De plus, nous avons évalué l'utilisation potentielle de ces sous-produits de l'industrie de la pastèque dans le développement de produits cosmétiques. Les acides gras les plus abondants dans l'huile de graines et la cire de pelure étaient l'acide linoléique et l'acide arachidique, respectivement. Les acides gras forment un composant essentiel des membranes cellulaires et sont de plus en plus reconnus dans l'industrie cosméceutique. Les antioxydants jouent également un rôle bénéfique dans les soins de la peau en combattant les radicaux libres résultant des dommages causés par le soleil et les polluants. L'huile de graines a montré une activité antioxydante plus forte que la cire issue de la peau, comme l'indique la capacité de piégeage des radicaux DPPH de $0,894 \mathrm{mg}$ d'équivalent $\alpha$-tocophérol/g de graines séchées contre $0,036 \mathrm{mg}$ d'équivalent $\alpha$-tocophérol/g de peaux séchées. Par conséquent, l'huile de graines a été formulée en produits de soins de la peau, sous forme d'émulsions et de nanoémulsions. Les formules les plus efficaces étaient stables à température ambiante pendant sept jours, ou après des cycles

\footnotetext{
Th Contribution to the Topical Issue "Lipids and Cosmetics / Lipides

et cosmétiques".

*Correspondence: waeowalee@go.buu.ac.th
} 
répétés de chauffage et de refroidissement. Ce travail démontre le potentiel de l'huile de pépins de pastèque dans les formulations de produits de soins de la peau, ce qui pourrait optimiser le profit agricole et réduire les déchets environnementaux.

Mots clés : Pastèque / pépins / pelures / antioxydant / nanoémulsion

\section{Introduction}

Watermelon (Citrullus lanatus) is a globally cultivated fruit, valued for its sweet flavor, high water content, and lowcalorific value (Maoto et al., 2019). In 2018, global watermelon usage stood at 166 million tons (FAOSTAT Statistical Database, Food and Agriculture Organization of the United Nations, 2020). However, while watermelon seeds are used in some regions of Asia for snacks and flour $(\mathrm{Hu}$, 2005), and watermelon peels are sometimes pickled (Gusmini and Wehner, 2004) or used as a cooked vegetable (Terry, 2009), both resources are more frequently discarded generating huge quantities of undervalued seed and peel wastes. The oil content of watermelon seeds is in the range of $10-35 \%$, varying depending on the genotype (Ziyada and Elhussien, 2008; Mahla et al., 2018). Watermelon seed oil is reported to be a good source of essential fatty acids, carotenoids, tocopherols, thiamine, flavonoid, riboflavin, and other phenolic substances, quantities of which vary depending on watermelon variety and extraction method (Ouassor et al., 2020). Linoleic acid is the most abundant fatty acid found in watermelon seed oil irrespective of variety. In addition, various bioactivities of the watermelon seed oil have been reported including: antioxidant-, anti-inflammatory-, cardioprotective- and antimicrobial activities (Eidangbe et al., 2010; Madhavi et al., 2012; Jorge et al., 2015; Bello et al., 2016; Thongtha et al., 2017). Therefore, watermelon seed oil could be a good alternative source of plant-derived oil for consumption and pharmaceutical applications (Biswas, 2017). Watermelon rind represents another underutilized resource, components of which include carbohydrates, fiber and wax (Al-Sayed and Ahmed, 2013; Morais et al., 2017). To date, limited information is known about the fatty acid profile of watermelon outer peels. Various efforts have been undertaken to utilize watermelon rind waste in food products, such as low glycemic cookies and cakes (Al-Sayed and Ahmed, 2013; Naknaen et al., 2016). However, little information exists concerning formulation of lipids from either seeds or peels of the Kinnaree variety of watermelon for use in cosmeceutical products.

The skin is the largest organ of the human body. While the dermis is hydrophilic, the outer surface of the skin is hydrophobic, and presents a significant barrier affecting transdermal absorption of therapeutic agents. However, given the lipophilic nature of skin, lipid-based delivery systems provide an efficient method to bypass this constraint. Emulsions and nanoemulsions are both commonly used in cosmetic and pharmaceutical applications to deliver both hydrophilic and lipophilic active compounds across the barrier (Otto and Plessis, 2015). Emulsions offer better organoleptic properties than oily solutions being non-greasy, non-staining and washable. Moreover, the small particle size of emulsions promotes higher absorption of active ingredients compared to oil-based solutions (Sakata et al., 2014). Various studies indicate that nanoemulsions demonstrate improved transdermal drug permeation compared to conventional topical formulations (Elmataeeshy et al., 2018; Shaker et al., 2019). Nanoemulsions are isotropic, transparent (translucent) systems consisting of oil, water, and surfactant. They generally have a droplet diameter in the 10 to $100 \mathrm{~nm}$ range (Arora et al., 2014). Nanoemulsions increase drug solubility, are easy to fabricate, and possess longer-term stability than conventional topical formulations, such as emulsions and ointments. The nano-range droplet size of nanoemulsions provides a relatively large surface area compared to conventional topical preparations and enhance the bioavailability of the drug. In addition, because less surfactant is required in nanoemulsions (5$20 \% \mathrm{w} / \mathrm{w}$ ) compared to microemulsions, the chance of skin irritation is significantly decreased and production costs reduced (Maruno and da Rocha-Filho, 2009; Rinaldi et al., 2017).

The aim of this study was to: (1) extract the lipid from watermelon seeds and peels (Kinnaree cultivar), (2) characterize their fatty acid compositions and (3) evaluate their antioxidant activities. A solvent extraction method performed at room temperature was employed to preserve the active ingredients. Formulation of extracted oil for topical use as emulsions and nanoemulsions were demonstrated; and the physical properties of each formulation were evaluated. This work highlights the significant potential of watermelon seed oil for use in the cosmeceutical industry. This could have the dual benefit of helping increase the value of byproducts of the watermelon industry and in decreasing the amount of agricultural waste from the watermelon consumption.

\section{Materials and methods}

\subsection{Materials}

Watermelon seeds and peels were provided by Nicha farm, Chonburi, Thailand. Tween 20, Tween 60, Tween 80 were purchased from P.C. Drug Center Co., Ltd., (Bangkok, Thailand). Span 20 and Span 80 were obtained from CT chemical (Bangkok, Thailand). Standard fatty acid methyl esters (FAMEs), 2-2'-diphenyl-1-picrylhydrazyl (DPPH), low viscosity sodium carboxymethyl cellulose (SCMC), boron trifluoride and $\alpha$-tocopherol were supplied by Sigma-Aldrich (Saint-Louis, MO, USA). N-hexane, methanol and heptane were purchased from Merck (Darmstadt, Germany). All other chemicals and reagents were of analytical or chromatographic grade.

\subsection{Extraction of watermelon seeds and peels}

Seeds and outer peels were obtained from the Kinnaree watermelon grown in the Chonburi province, Thailand. 
The whole seeds and outer peels were dried in a hot air oven (Memmert ${ }^{B}$ CTC256, Buchenbach, Germany) at $60^{\circ} \mathrm{C}$ until a stable weight was obtained. Both seeds and peels were then ground into a fine powder and kept at $4{ }^{\circ} \mathrm{C}$ with desiccant. Lipid extraction was performed by immersing the powdered seeds or peels in hexane at a ratio of $1 \mathrm{~g}: 2 \mathrm{~mL}$ and $1 \mathrm{~g}: 5 \mathrm{~mL}$, respectively. The mixture was incubated at room temperature for $2,6,12$ and $24 \mathrm{~h}$ prior to filtration using Whatman No.1 filter paper. The solvent was then removed from the filtrate using a SpeedVac concentrator (Thermo Fisher Scientific, Waltham, MA, USA). The oil yield was calculated using the equation; \% yield = weight of extracted oil or wax / dry weight of seeds or peels.

\subsection{Determination of fatty acid composition}

\subsubsection{Preparation of fatty acid methyl esters (FAMEs)}

FAMEs were prepared using the methods reported by Yurchenko et al. (2016) with slight modification. Watermelon seed oil $(100 \mu \mathrm{L})$ was mixed with $800 \mu \mathrm{L}$ of $0.5 \mathrm{M}$ methanolic $\mathrm{NaOH}$ and heated at $80{ }^{\circ} \mathrm{C}$ for $7 \mathrm{~min}$. After cooling down to room temperature, $900 \mu \mathrm{l}$ of $20 \%$ methanolic boron trifluoride was added to the reaction mixture and incubated at $80^{\circ} \mathrm{C}$ for a further $2 \mathrm{~min}$. Heptane $(400 \mu \mathrm{L})$ was added to the mixture prior to incubation at $100{ }^{\circ} \mathrm{C}$ for $1 \mathrm{~min}$. FAMEs were separated from the reaction mixture by addition of $1500 \mu \mathrm{L}$ saturated $\mathrm{NaCl}$, and following phase separation the upper phase was collected. FAMEs were stored at $-20^{\circ} \mathrm{C}$ until use. For extraction of peel wax, a similar FAME extraction procedure was employed; however, peel wax was dissolved in $100 \mu \mathrm{l}$ heptane prior to heating in $800 \mu \mathrm{L}$ of $0.5 \mathrm{M}$ methanolic $\mathrm{NaOH}$ at $80^{\circ} \mathrm{C}$ for $7 \mathrm{~min}$.

\subsubsection{Analysis of FAMEs by gas chromatography}

FAME standards were used for both qualitative and quantitative analysis of the fatty acid composition of seed oil and peel wax. Standards used for this analysis were caprylic acid (C8:0), capric acid (C10:0), lauric acid (C12:0), myristic acid (C14:0), palmitic acid (C16:0), palmitoleic acid (C16:1), stearic acid (C18:0), oleic acid (C18:1), linoleic acid (C18:2), arachidic acid (C20:0), linolenic acid (C18:3), behenic acid (C22:0), erucic acid (C22:1), and lignoceric acid (C24:0). For quantitative analysis, 6 concentrations $(1,10,20,40,60$, and $100 \mathrm{mg} / \mathrm{mL})$ of the mixed standards were analyzed, to allow construction of a standard curve of each fatty acid. FAMEs (standards or extracted samples) were analyzed using a 6890-gas chromatograph (Agilent Technologies, Palo Alto, CA) connected to a HP-FFAP column $(30 \mathrm{~m} \times 0.25 \mathrm{~mm}$ i.d. $\times 0.25 \mu \mathrm{m})$. One microliter of each sample was injected in to the instrument using spitless injection at a temperature of $200{ }^{\circ} \mathrm{C}$. Helium was used as a carrier gas. The oven temperature was programmed to range between $150{ }^{\circ} \mathrm{C}$ and $220^{\circ} \mathrm{C}$, with the temperature increasing at a rate of $4{ }^{\circ} \mathrm{C} / \mathrm{min}$, followed by constant heating at $220^{\circ} \mathrm{C}$ for $20 \mathrm{~min}$. Eluted substances were detected by a flame ionization detector. All data were acquired using the Agilent ChemStation software.

\subsection{Antioxidant activities of watermelon seed oil extract}

Potential antioxidant activities were assessed in vitro by measuring the quenching efficacy of 2,2-diphenyl-1picrylhydrazyl (DPPH) radicals (Molyneux, 2004). In brief, known concentrations of extracted seed oil or peel wax, in heptane $(50 \mu \mathrm{L})$, were mixed with $100 \mu \mathrm{L}$ of $0.2 \mathrm{mM}$ DPPH in methanol in a 96-well plate. The plate was then incubated at room temperature, in the dark, for $30 \mathrm{~min}$. Following incubation, absorbance was measured at $517 \mathrm{~nm}$ using a VersaMax microplate reader (Molecular Devices, Sunnyvale, CA, USA). The \% DPPH inhibition was calculated using the equation; $\%$ inhibition $=\left(A_{\text {Control }}-A_{\text {Sample }}\right) /\left(A_{\text {Control }}\right) \times 100$; where A represents absorbance at $517 \mathrm{~nm}$. Solutions of $\alpha$-tocopherol at $10,25,50,75$ and $100 \mu \mathrm{g} / \mathrm{mL}$ were used as positive controls. Half maximal inhibitory concentration (IC50) values were determined from the graphed values of percentage of DPPH quenching, versus sample concentrations, using Microsoft Excel 2016 (Microsoft, Redmond, WA, USA). All experiments were performed in triplicate. Statistical analysis was carried out employing the one-way analysis of variance (ANOVA) and Tukey's post tests using a Minitab 18 software (Minitab Inc., State College, PA, USA).

\subsection{Formulation of watermelon seed oil extract}

Potential dosage forms of watermelon seed oil extract in both emulsion and nanoemulsion forms were prepared using biphasic systems as outlined below. The liquid phases were evaluated for physical properties and stability.

\subsubsection{Preparation of emulsions}

Emulsions were formulated using the beaker method as indicated in Table 1. The major components of the final watermelon seed oil extract emulsion consisted of the seed oil, surfactant (Tween 80 and Span 80), water and pharmaceutical excipients such as stiffening agent (Stearyl alcohol and glyceryl monostearate), humectant (propylene glycol), and suspending agent (SCMC).

Briefly, the emulsions were prepared as follows: the oil phase (see Tab. 1 upper panel) containing surfactant and watermelon seed oil extract was heated in a water bath to $72^{\circ} \mathrm{C}$, and the water phase (see Tab. 1 lower panel) heated in parallel to $75^{\circ} \mathrm{C}$. Then, both clear solutions were thoroughly mixed. The resulting emulsion formulations were kept in a tightly sealed glass container, at room temperature, until use. Following storage, emulsion formulations were evaluated for their $\mathrm{pH}$, stability and their morphology assessed by microscopy.

\subsubsection{Preparation of nanoemulsions}

Watermelon seed oil extract nanoemulsions were prepared using ultrasonication with a Vibra Cell VCX 750 sonicator (Sonics Materials Inc., USA). Briefly, watermelon seed oil extract, surfactant, and water were taken in a beaker and mixed under continuous stirring for $30 \mathrm{~min}$. Tween 20, Tween 60 , Tween 80, Span 20, and Span 80 were employed as surfactants. The oil concentration to surfactant concentration ratio was 
Table 1. The composition of watermelon seed oil extract emulsions.

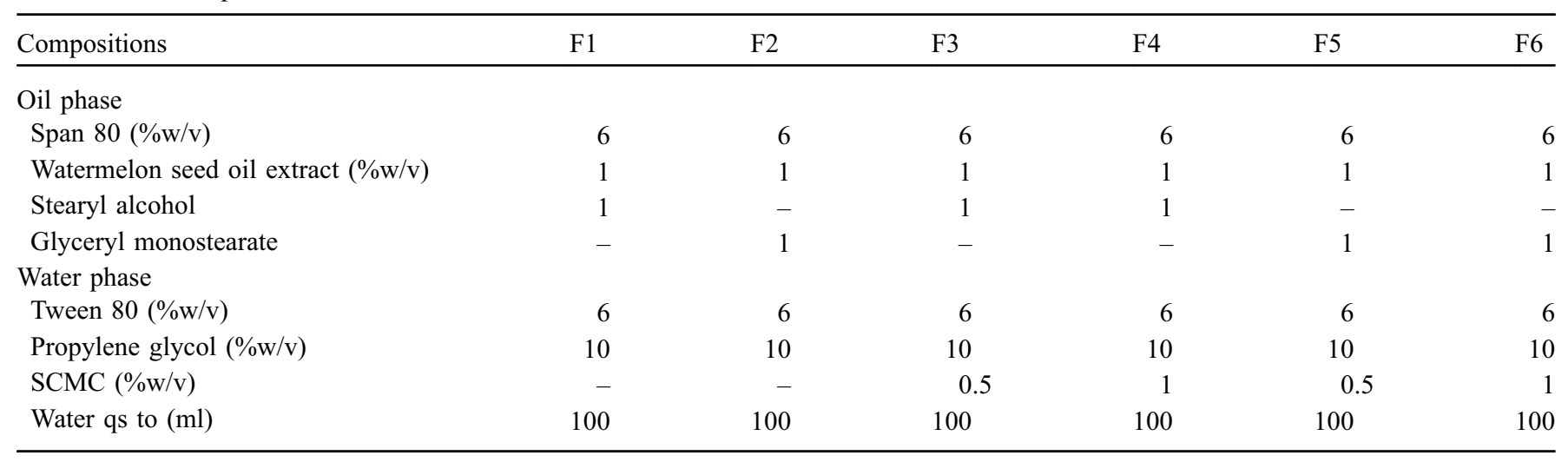

$1: 10,1: 15$ and $1: 20$ in a final volume of $20 \mathrm{ml}$. The mixture was sonicated for $5 \mathrm{~min}$ at $40 \%$ amplitude in an ice bath resulting in the formation of nanoemulsions.

Correctly prepared nanoemulsion formulations selected for further study were transparent and clear. Cloudy or milky/ white solutions were excluded from this study. Nanoemulsions was analyzed to ascertain $\mathrm{pH}$, droplet size, and stability.

\subsection{Evaluation of formulations}

\subsubsection{Determination of emulsion and nanoemulsion $\mathrm{pH}$}

Emulsion and nanoemulsion $\mathrm{pH}$ were measured in triplicate, at $25^{\circ} \mathrm{C}$, using a $\mathrm{pH}$ meter (Mettler Toledo MP 220, Greifensee, Switzerland).

\subsubsection{Microscopic analysis of emulsion structure}

Emulsions were stained with Ponceau 4R aqueous solution, and their morphology analyzed using a light microscope (Axio Lab. A1, Carl Zeiss, Germany) connected to an EOS 80D camera (Canon, Japan). All images were captured using a Zeiss Axiovision LE software (Carl Zeiss, Germany).

\subsubsection{Determination of nanoemulsion droplet size}

Nanoemulsion droplet size was determined by dynamic light scattering using a Zetasizer Nano ZS particle and molecular size analyzer (Malvern Instrument Ltd., Worcestershire, UK). The nanoemulsion was diluted 1 in 200 with distilled water in a microcentifuge tube $(1.5 \mathrm{ml})$ (Eppendorf, NY, USA). The prepared samples were analyzed to determine droplet size, polydispersity index (PDI), and zeta potential. Triplicate dilutions of each sample were analyzed.

\subsubsection{Assessment of emulsion stability}

Prepared emulsion formulations were stored in a clear glass bottle, with a tightly sealed rubberized cap for stability testing. This study evaluated the stability of both emulsions and nanoemulsions under two different conditions: (1) storage at $25^{\circ} \mathrm{C}$ for seven days to replicate regular storage, (2) six cycles of a heating-cooling cycle to assess the effect of extreme temperature changes. The heating-cooling cycle consisted of storing the samples in a hot air oven (Memmert CTC256,
Buchenbach, Germany) at $40^{\circ} \mathrm{C}$ for $48 \mathrm{~h}$ followed by a cooling period in a refrigerator (Panasonic ${ }^{\circledR}$ NR-BU303 SSTH, Osaka, Japan) at $4{ }^{\circ} \mathrm{C}$ for $48 \mathrm{~h}$. Physicochemical characteristics (droplet size, PDI, and $\mathrm{pH}$ ) were evaluated before and after the stability studies $(n=3)$. The statistical analysis was performed using a paired t-test (Minitab Inc., State College, PA, USA). Emulsion and nanoemulsions which displayed instability in the form of turbidity, creaming, cracking, and phase separation were excluded from study. All preparations were observed visually for any turbidity or phase separation. Emulsion creaming was also measured, creaming being defined as the migration of the dispersed phase, under the influence of buoyance, i.e. phase separation. The creaming index $(\% \mathrm{CI})$ was calculated as the following: $\% C I=(C C / C T) \times 100$; where $\mathrm{CC}$ is the total height of the cream layer/upper phase and $\mathrm{CT}$ is the total volume height.

\section{Results and discussion}

\subsection{Extraction of watermelon seed oil and peel wax}

Fresh watermelons (Kinnaree cultivar) were utilized for extraction of seed oil and peel wax (Figs. 1A and 1E). To extract oil from watermelon seeds, the seeds were first dried at $60{ }^{\circ} \mathrm{C}$ to remove water, prior to extraction. The dried seeds measured approximately $5 \mathrm{~mm}$, and were composed of outer seed peels and kernels. Whole dried seeds were ground to increase surface area to optimize the extraction process (Figs. 1B and 1C). Following oil extraction, a light-yellow colored and odorless oil was obtained (Fig. 1D). To extract lipid from watermelon outer peels, peels were first dried at $60^{\circ} \mathrm{C}$ and ground (Figs. $1 \mathrm{~F}$ and $1 \mathrm{G}$ ). Following solvent extraction and evaporation, a dark green, soft-solid wax was obtained (Fig. 1H). The yields of both seed oil and peel wax following hexane extraction are shown in Table 2. Extraction times of 2-24h were tested, with increased extraction times leading to higher yields of both seed oil and peel wax. Extraction for $24 \mathrm{~h}$ provided the maximum yield of fatty acids and was used as standard in our extraction procedures. Extractions were performed at room temperature to preserve active compounds and prevent oxidation. As a result of our reluctance to use higher temperatures, the oil yield of watermelon seed oil in our study were lower than those from previously published reports (Ziyada and Elhussien, 2008; Mahla et al., 2018). 
A

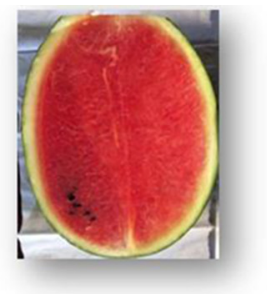

E

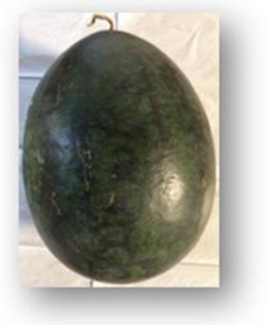

B

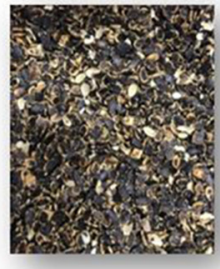

F

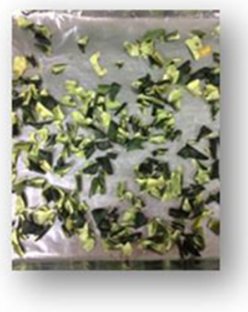

C

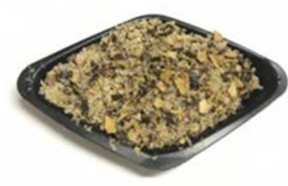

G

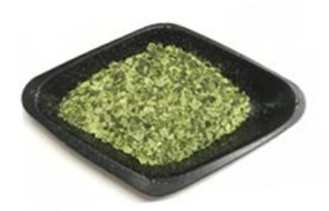

D

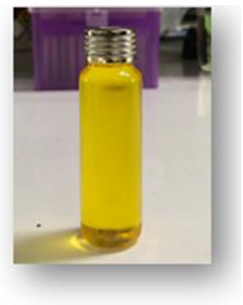

$\mathrm{H}$

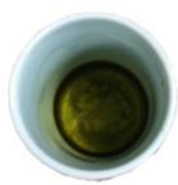

Fig. 1. Images of (A) Kinnaree watermelon seeds in situ within a halved fruit; (B) dried seeds; (C) ground seeds; (D) oil extracted from the seeds; (E) outer peel of Kinnaree watermelon; $(F)$ dried peels; $(\mathrm{G})$ ground peels and $(\mathrm{H})$ peel wax.

Table 2. Extraction yield (\%yield) of the extracted seed oil and peel wax $(\mathrm{g} / 100 \mathrm{~g}$ of dried seeds and dried peels).

\begin{tabular}{lll}
\hline \multirow{2}{*}{$\begin{array}{l}\text { Extraction time } \\
\text { (h) }\end{array}$} & \multicolumn{2}{c}{$\%$ yield (mean \pm SD) } \\
\cline { 2 - 3 } & Seeds & Peels \\
\hline 2 & $4.466 \pm 4.274$ & $0.187 \pm 0.265$ \\
6 & $5.167 \pm 5.061$ & $0.585 \pm 1.676$ \\
12 & $7.098 \pm 1.889$ & $1.155 \pm 1.096$ \\
24 & $7.721 \pm 4.609$ & $1.422 \pm 0.746$ \\
\hline
\end{tabular}

\subsection{Fatty acid composition in watermelon seed oil and peel wax}

Fatty acids were separated by gas chromatography and the analytes within the gas stream identified and quantified using a flame ionization detector (FID). Methyl esters of 14 common fatty acids found in seed oils were used as analytical standards. The elution order of the FAMEs was as follows: caprylic acid (C8:0), capric acid (C10:0), lauric acid (C12:0), myristic acid (C14:0), palmitic acid (C16:0), palmitoleic acid (C16:1), stearic acid (C18:0), oleic acid (C18:1), linoleic acid (C18:2), arachidic acid (C20:0), linolenic acid (C18:3), behenic acid (C22:0), erucic acid (C22:1), and lignoceric acid (C24:0), respectively (Fig. 2A). The seed oil contained 8 fatty acids each of 14-20 carbon atoms. Four of these were saturated fatty acids; myristic acid, palmitic acid, stearic acid and arachidic acid. Two fatty acids were classified as mono-unsaturated fatty acids; palmitoleic acid and oleic acid. And the other two fatty acids were poly-unsaturated fatty acids; linoleic acid, and linolenic acid (Fig. 2B). The watermelon peel wax contained a smaller number of fatty acids with 14-20 carbon atoms. These were myristic acid, palmitic acid, stearic acid, oleic acid, linoleic acid, and arachidic acid (Fig. 2C.).

Based on the proportional concentration of each fatty acid (\% of total fatty acid) estimated from the area under the chromatographic peak, the most abundant fatty acids found in the seed oil was linoleic acid, which accounted for $60.10 \pm 1.87 \%$ of total fatty acid, followed by oleic acid $(17.57 \pm 0.74 \%)$ and palmitic acid $(12.08 \pm 3.62 \%)$, respectively (Fig. 3). Our results, obtained using hexane extraction of seed oil from the Kinnaree cultivar were in agreement with data from the previous literature assessing the relative amounts of these three major fatty acids from other cultivars using different extraction methods. For comparison, linoleic acid, oleic acid, and palmitic acid were previously reported to be in a range of $45.1-76.2 \%, 0.33-33.66 \%$, and $4.30-16.2 \%$, respectively (Biswas, 2017).

Our analysis of watermelon peel wax indicated that the top three most abundant fatty acids were arachidic acids $(40.96 \pm 2.27 \%)$, palmitic acid $(28.42 \pm 3.30 \%)$ and linoleic acid $(15.86 \pm 0.77 \%)$ as shown in Figure 3. The high proportion of arachidic acid, a saturated long-chain fatty acid, in the hexane extracted peels, was not surprising given that the wax-like extract was highly viscous and semi-solid. However, a previous study using watermelons grown in Brazil indicated a different profile, in which the most abundant fatty acid was palmitic acid; while only a small quantity of arachidic acid was observed (Morais et al., 2017). It is plausible that different varieties of watermelon possess greater variation in the fatty acid profiles of their peels than the seeds.

\subsection{Antioxidant activity of watermelon seed oil and peel wax}

The antioxidant activity of seed oil and peel wax was determined by the ability to scavenge DPPH radicals compared to a positive control ( $\alpha$-tocopherol). The seed oil extract possessed a higher DPPH radical quenching ability than the peel wax, $0.894 \mathrm{mg} \alpha$-tocopherol equivalent/g dried seeds versus $0.036 \mathrm{mg} \alpha$-tocopherol equivalent/g dried peels. Antioxidant activity was also calculated in terms of IC50 values. These also indicated stronger antioxidant activity in seed oil extracts than in peel wax. However, activities never exceeded that of the positive control ( $\alpha$-tocopherol) (Tab. 3). 


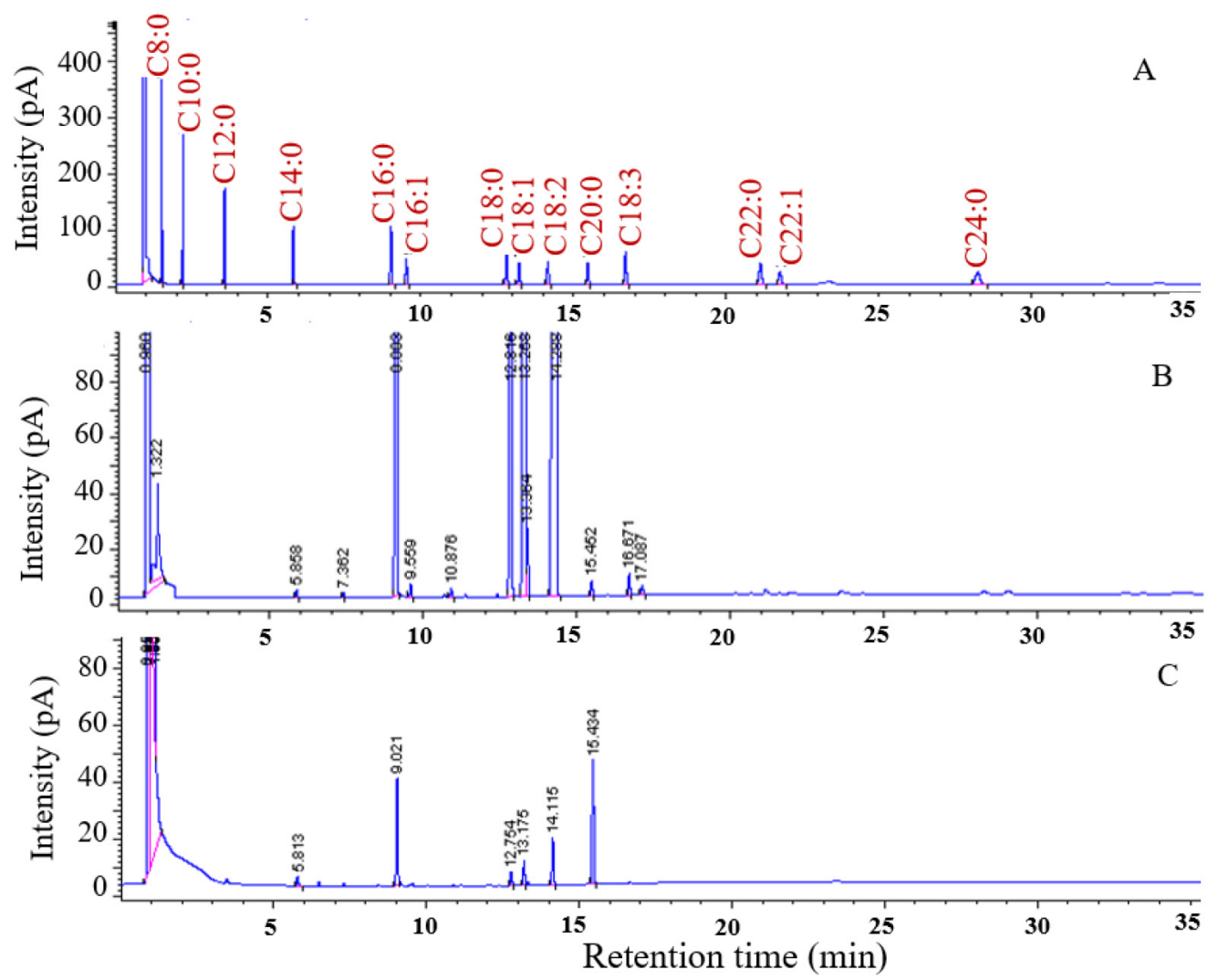

Fig. 2. Chromatograms of (A) standard FAMEs; (B) FAMEs of watermelon seed extract and (C) FAMEs of watermelon outer peel extract.

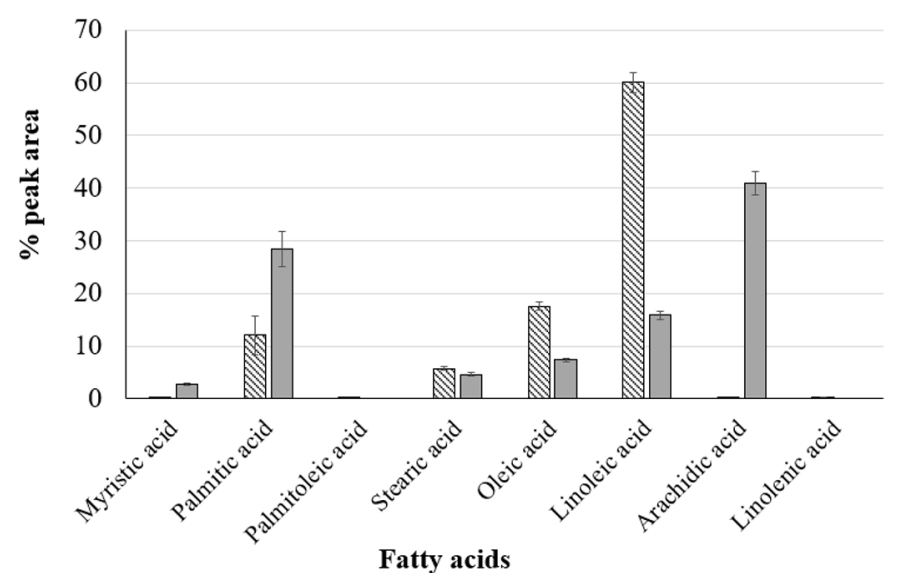

Fig. 3. The percentage of fatty acids presented in watermelon seeds (ख) and peels $(\square)$ (as a \% of total fatty acid).

As a result of higher antioxidant activity, seed oil was chosen for formulation of skin care products, in the form of emulsions and nanoemulsions.

\subsection{Analysis of emulsion properties and storage potential}

Watermelon seed oil extract emulsions were stained with Ponceau 4R, a water-soluble dye and analyzed by light microscopy. The emulsions contained large globular droplets
Table 3. IC 50 values (mean \pm SD) determined from DPPH radical scavenging assays. Different letters indicate significant differences among the samples (ANOVA $P<0.05$ ).

\begin{tabular}{ll}
\hline Sample & IC50 \\
\hline$\alpha$-tocopherol & $50.46 \pm 1.37 \mu \mathrm{g} / \mathrm{mL}^{\mathrm{a}}$ \\
Seed oil extract & $3653.29 \pm 539.31 \mu \mathrm{g} / \mathrm{mL}^{\mathrm{b}}$ \\
Peel wax extract & $8000 \mu \mathrm{g} / \mathrm{mL}^{\mathrm{c}}$ \\
\hline
\end{tabular}

in the micrometer size range (Fig. 4). This confirmed that watermelon seed oil extract emulsions were an oil-in-water emulsion because the aqueous color solution was stained outside an oil droplet. Emulsion stability was tested following two conditions: 1) 7 days storage at room temperature $\left(25^{\circ} \mathrm{C}\right)$, and 2) following 6 heating and cooling cycles (the samples were heated in a hot air oven at $40^{\circ} \mathrm{C}$ for $48 \mathrm{~h}$ followed by a cooling period in a refrigerator at $4{ }^{\circ} \mathrm{C}$ for $48 \mathrm{~h}$ ). Six different emulsion formulations were tested, containing different amounts of stiffening agents and suspending agent (Tab. 1). Following storage at the indicated experimental conditions the $\mathrm{pH}$ of each formulation was assessed (Tab. 4). The $\mathrm{pH}$ values of all stored samples were lower than those of the freshly prepared samples. The decreasing $\mathrm{pH}$ values after 7 days of storage may be a result of free fatty acids that occurred after the hydrolysis of watermelon seed oil extract.

The different formulations displayed different physical properties depending on the amounts of stiffening agents 
Table 4. The properties of watermelon seed-oil emulsions following storage.

\begin{tabular}{|c|c|c|c|c|c|}
\hline \multirow[t]{2}{*}{ Formulation } & \multirow[t]{2}{*}{$\mathrm{pH}$ of freshly prepared } & \multicolumn{2}{|c|}{ After 7 days } & \multicolumn{2}{|c|}{ After 6 cycles } \\
\hline & & $\mathrm{pH}$ & $\% \mathrm{CI}$ & $\mathrm{pH}$ & $\% \mathrm{CI}$ \\
\hline F1 & $6.82 \pm 0.042$ & $6.65 \pm 0.038^{*}$ & $72.00 \pm 9.14$ & N/A & N/A \\
\hline F3 & $7.03 \pm 0.025$ & $6.63 \pm 0.015^{*}$ & Undetectable & $5.67 \pm 0.091^{*}$ & $65.56 \pm 12.62$ \\
\hline F4 & $6.90 \pm 0.006$ & $6.62 \pm 0.025^{*}$ & Undetectable & $5.59 \pm 0.050^{*}$ & Undetectable \\
\hline
\end{tabular}

${ }^{*}$ Asterisks indicate statistically significant differences $(P<0.05)$ between the $\mathrm{pH}$ values of the samples before and after the stability tests.

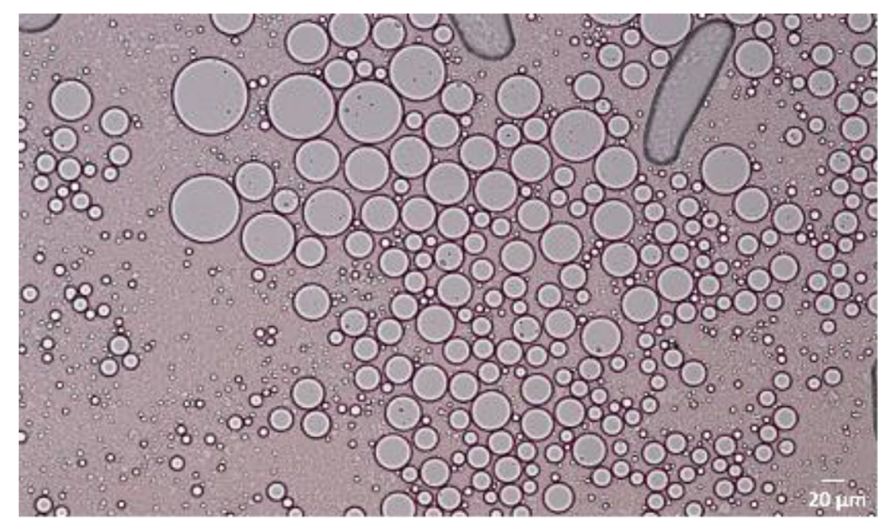

Fig. 4. The morphology of emulsion droplets as stained by Ponceau $4 R$ and imaged by light microscopy. The scale bar indicates $20 \mu \mathrm{m}$.

added during formulation. Increased concentrations of stearyl alcohol and glyceryl monostearate (stiffening agents) provided harder texture; while an increased concentration of SCMC provided higher viscosity. Attempts at preparing a formulation without SCMC did not result in a stable emulsion. The emulsion separated into an upper optically opaque droplet-rich layer (creaming layer) and a transparent lower layer, through gravitational separation thus deeming this formulation undesirable. The creaming layer was quantified as a percentage of total emulsion volume and could be decreased by addition of SCMC. Higher SCMC concentrations increased viscosity of the aqueous phase and improved emulsion stability by inhibiting droplet aggregation, in agreement with a previous study (Huan et al., 2016). Formulations F4 and F6 containing high percentages of SCMC were both stable after storage at room temperature for seven days and following subjection to heating-cooling cycles (Fig. 5). These data indicate that emulsions formulated using watermelon seed oil extract demonstrate sufficient stability for use in cosmeceuticals. Further optimization of $\mathrm{pH}$ and excipients such as adjustment agents, and preservatives would need to be optimized for use in skin products (Tiwari, 2007).

\subsection{Analysis nanoemulsion properties and storage potential}

Watermelon seed oil extract nanoemulsions consisted of a mixture of seed oil, surfactant, and water. Our studies

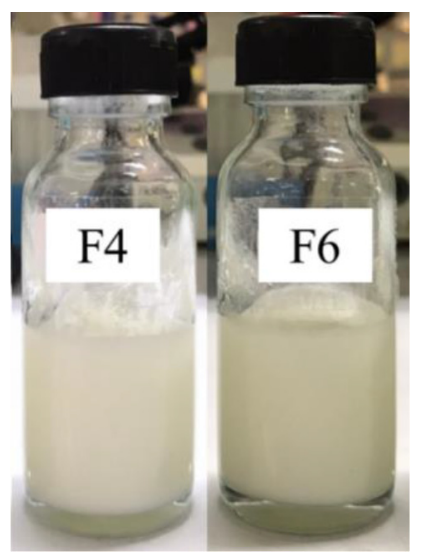

Fig. 5. Stable emulsion after the 7 days or 6 cycles test.

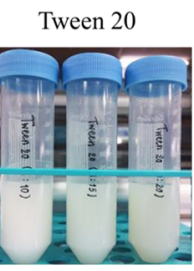

$1: 10 \quad 1: 15 \quad 1: 20$
Tween 60

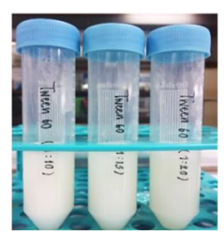

$1: 10 \quad 1: 15 \quad 1: 20$

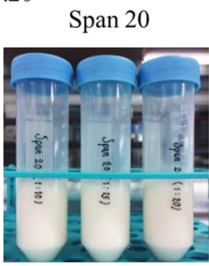

$1: 10 \quad 1: 15 \quad 1: 20$
Tween 80

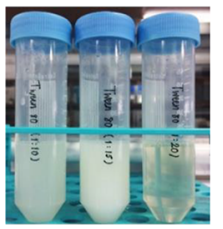

$1: 10 \quad 1: 15 \quad 1: 20$
Span 80

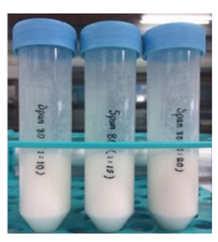

$1: 10 \quad 1: 15 \quad 1: 20$

Fig. 6. The appearance of all formulations following probe sonication.

indicated that the optimum ratio of oil and Tween 80 was 1:20. This resulted in a transparent and clear solution while other surfactants resulted in turbid and milky solutions unsuitable for our purposes (Fig. 6). The pH value, droplet size, and zeta potential of the optimal formulation are shown in Table 5. After stability tests under both conditions, the appearance of nanoemulsion was transparent and did not change as ascertained by visual inspection. In addition, the droplet size remained constant, lower than $20 \mathrm{~nm}$, and the zeta potential did 
Table 5. The $\mathrm{pH}$ value, droplet size, and zeta potential of the optimal formulation.

\begin{tabular}{|c|c|c|c|c|}
\hline Sample & $\mathrm{pH}$ & \multicolumn{2}{|c|}{ Droplet size } & Zeta potential \\
\hline Freshly prepared & $7.41 \pm 0.02$ & $15.87 \pm 1.81$ & $0.410 \pm 0.026$ & $-7.99 \pm 1.96$ \\
\hline After 7 days & $7.20 \pm 0.03^{*}$ & $18.39 \pm 1.57$ & $0.496 \pm 0.074$ & $-7.15 \pm 1.56$ \\
\hline After 6 cycles & $6.93 \pm 0.01^{*}$ & $14.08 \pm 2.40$ & $0.263 \pm 0.033$ & $-7.61 \pm 0.47$ \\
\hline
\end{tabular}

*Asterisks indicate statistically significant differences $(P<0.05)$ between the $\mathrm{pH}$ values, droplet size, and zeta potential of the samples before and after the stability tests.

not significantly change. These data indicated overall stability of the nanoemulsion formulation and indicated its potential for use as a cosmetic product. However, the $\mathrm{pH}$ values of the nanoemulsions decreased under both storage conditions $(P<0.05)$, like the changes observed for the emulsion formulations. For consideration as a cosmeceutical, the formulation would need to be adjusted and stabilized at $\mathrm{pH}$ 5.5-6 in order to be suitable for the skin. Besides the addition of $\mathrm{pH}$ adjustment agents, pharmaceutical additives, coloring agents, flavoring agents, and preservatives could also be included in the final formulation (Tiwari, 2007).

\section{Conclusions}

This study reveals that watermelon (Kinnaree cultivar) seeds and peels are rich in various fatty acids which are suitable for use in cosmeceutical formulations. These two byproducts of the watermelon industry contained distinct profiles of essential fatty acids. Our comparative study indicated that seed oil possessed stronger antioxidant activity than that of peel wax. Therefore, seed oil should be more effective than peel wax as an additive in cosmeceutical products to reduce and prevent cellular damage, a major cause of skin aging. Two forms of cosmeceutical products, emulsions and nanoemulsions, were successfully formulated from watermelon seed oil extract. Stable emulsions were successfully formulated with either stearyl alcohol or glyceryl monostearate and 1\% SCMC. Furthermore, stable nanoemulsions were developed using watermelon seed oil and Tween 80 at a ratio of 1:20, resulting in transparent and clear solutions. Our data suggest the potential use of watermelon seed oil as a component in cosmeceutical products. These findings would be beneficial for the future development of value-added products from watermelon seeds, which are considered to be widely available agricultural and food waste.

\section{Conflict of interest}

The authors declare the absence of any conflicts of interest.

Acknowledgements. Financial support from the Center of Excellence for Innovation in Chemistry (PERCH-CIC), Office of the Higher Education Commission, Ministry of Education is gratefully acknowledged. Mark I. McDermott is supported by funding from the Robert A. Welch Foundation (BE0017), and a grant from the National Institutes of Health (GM131804) both awarded to Vytas A. Bankaitis. Watermelons used in this study were kindly provided by Nicha farm, Chonburi, Thailand.

\section{References}

Al-Sayed HMA, Ahmed AR. 2013. Utilization of watermelon rinds and sharlyn melon peels as a natural source of dietary fiber and antioxidants in cake. Ann Agric Sci 58(1): 83-95.

Arora R, Aggarwal G, Harikumar SL, Kaur K. 2014. Nanoemulsion based hydrogel for enhanced transdermal delivery of ketoprofen. Adv Pharm 7: 1-12.

Bello HS, Ismail HY, Goje MH, Mangga HK. 2016. Antimicrobial activity of Citrullus lanatus (watermelon) seeds on some selected bacteria. J Biotechnol Res 2(6): 39-43.

Biswas R. 2017. A comprehensive review on watermelon seed oil-An underutilized product. IOSR J Pharm 7(11): 01-07.

Eidangbe GO, Ojieh G, Idonije B, Oluba O. 2010. Palm oil and Egusi melon oil lower serum and liver lipid profile and improve antioxidant activity in rats fed a high fat diet. J Food Technol 8: 154-158.

Elmataeeshy ME, Sokar MS, Bahey-El-Din M, Shaker DS. 2018. Enhanced transdermal permeability of Terbinafine through novel nanoemulgel formulation; Development, in vitro and in vivo characterization. Futur J Pharm Sci 4(1): 18-28.

FAOSTAT. 2020. Statistical database. Food and Agriculture Organization of the United Nations. Available from http:// www.fao.org/faostat/en/\#data/QC (last consult: 2020/25/06).

Gusmini G, Wehner TC. 2004. Cultivars suitable for watermelon rind pickles. Rep Cucurbit Genet Coop 27: 41-42.

Hu SY. 2005. Food plants of China. Hong Kong (China): The Chinese University of Hong Kong Press, $125 \mathrm{p}$.

Huan Y, Zhang S, Vardhanabhuti B. 2016. Influence of the molecular weight of carboxymethylcellulose on properties and stability of whey protein-stabilized oil-in-water emulsions. J Dairy Sci 99(5): 3305-3315.

Jorge N, Silva AC, Malacrida CR. 2015. Physicochemical characterisation and radical-scavenging activity of Cucurbitaceae seed oils. Nat Prod Res 295: 2313-2317.

Madhavi P, Rao M, Vakati K, Rahman H, Eswaraiah MC. 2012. Evaluation of anti-inflammatory activity of Citrullus lanatus seed oil by in-vivo and in-vitro models. Int Res J Pharm App Sci 2(4): 104-108.

Mahla HR, Rathore SS, Venkatesan K, Sharma R. 2018. Analysis of fatty acid methyl esters and oxidative stability of seed purpose 
watermelon (Citrullus lanatus) genotypes for edible oil. $J$ Food Sci Technol 55(4): 1552-1561.

Maoto MM, Beswa D, Jideani AIO. 2019. Watermelon as a potential fruit snack. Int J Food Prop 22(1): 355-370.

Maruno M, da Rocha-Filho PA. 2009. O/W nanoemulsion after 15 years of preparation: a suitable vehicle for pharmaceutical and cosmetic applications. J Disper Sci Technol 31(1): 17-22.

Molyneux P. 2004. The use of the stable free radical diphenylpicrylhydrazyl (DPPH) for estimating antioxidant activity. Songklanakarin J Sci Technol 26(2): 211-219.

Morais DR, Rotta EM, Sargi SC, et al. 2017. Proximate composition, mineral contents and fatty acid composition of the different parts and dried peels of tropical fruits cultivated in brazil. J Braz Chem Soc 28(2): 308-318.

Naknaen P, Itthisoponkul T, Sondee A, Angsombat N. 2016. Utilization of watermelon rind waste as a potential source of dietary fiber to improve health promoting properties and reduce glycemic index for cookie making. Food Sci Biotechnol 25(2): 415-424.

Otto A, du Plessis J. The effects of emulsifiers and emulsion formulation types on dermal and transdermal drug delivery. In: Dragicevic N, Maibach HI, eds. Percutaneous penetration enhancers chemical methods in penetration enhancement. Berlin (Germany): Springer Berlin Heidelberg, 2015, pp. 223-241.

Ouassor I, Aqil Y, Belmaghraoui W, Hajjaji SE. 2020. Characterization of two Moroccan watermelon seeds oil varieties by three different extraction methods. OCL 27: 13.
Rinaldi F, Hanieh PN, Longhi C, et al. 2017. Neem oil nanoemulsions: characterisation and antioxidant activity. $J$ Enzyme Inhib Med Chem 32(1): 1265-1273.

Sakata O, Fujii M, Koizumi N, Nakade M, Kameyama K, Watanabe Y. 2014. Effects of oils and emulsifiers on the skin penetration of stearyl glycyrrhetinate in oil-in-water emulsions. Biol Pharm Bull 37(3): 486-489.

Shaker DS, Ishak RAH, Ghoneim A, Elhuoni MA. 2019. Nanoemulsion: A review on mechanisms for the transdermal delivery of hydrophobic and hydrophilic drugs. Sci Pharm 87(3): 17.

Terry B. 2009. Vegan soul kitchen: fresh, healthy, and creative African-American cuisine. Massachusetts (USA): Da Capo Press, $86 \mathrm{p}$.

Thongtha S, Sawai P, Srisook K. 2017. A comparative study on antioxidant and nitric oxide-inducing activity of some watermelon cultivars grown in Thailand. Burapha Sci $J$ 22(Special issue): 14-22.

Tiwari SB. Nanoemulsion formulations for tumor targeted delivery. In: Amiji MM, ed. Nanotechnology for cancer therapy. New York (USA): CRC Press, 2007, pp. 723-40.

Yurchenko S, Sats A, Poikalainan V, Karus A. 2016. Method for determination of fatty acid in bovine colostrum using GC-FID. Food Chem 212: 117-122.

Ziyada AK, Elhussien SA. 2008. Physical and chemical characteristics of Citrullus lanatus var Colocynthoide seed oil. J Phys Sci 19(2): 69-75.

Cite this article as: Petchsomrit A, McDermott MI, Chanroj S, Choksawangkarn W. 2020. Watermelon seeds and peels: fatty acid composition and cosmeceutical potential. OCL 27: 54. 